\title{
PERANCANGAN APLIKASI DATA SERVIS KOMPUTER BERBASIS WEB DI MELLON KOMPUTER BANJARMASIN
}

\author{
Ihsanul Fikri' ${ }^{1)}$, Fauzi Yusa Rahman²), Aulia Rizky Muhammad Hendrik Noor Asegaff ${ }^{3)}$ \\ ${ }^{1)}$ Fakultas Teknologi Informasi, Universitas Islam Kalimantan MAB Banjarmasin \\ email: ihsan.fti@gmail.com \\ 2)Fakultas Teknologi Informasi, Universitas Islam Kalimantan MAB Banjarmasin \\ email: fauziyusarahman@gmail.com \\ ${ }^{3)}$ Fakultas Teknologi Informasi, Universitas Islam Kalimantan MAB Banjarmasin \\ email: aulia.rizky.m.h.n.a@gmail.com
}

\begin{abstract}
Abstrak
Mellon Komputer adalah suatu toko komuter yang bergerak khusus pada servis komputer, di toko ini menerima berbagai macam kerusakan peralatan komputer baik itu personal komputer, laptop, tablet, printer, dan lain-lain. Pada saat ini pengelolaan data servis hanya bersifat manual, yaitu pelanggan datang untuk memperbaiki komputernya, kemudian data pelanggan dicatat pada sebuah nota, nota terdiri dari dua lembar yaitu lembar putih dan lembar merah. Lembar merah di bawa oleh pelanggan, sedangkan lembar putih disimpan di toko. Apabila sudah selesai maka pelanggan harus menunjukkan nota merah untuk mengambil komputer yang sudah selesai di servis. Hal ini tentu saja memiliki kekurangan, yaitu data servis yang berupa nota tentu saja akan dapat hilang dan rusak, bahkan kesulitan bagi teknisi yaitu bagaimana mengingat data pelanggan dan data kerusakan komputer yang telah lalu, karna tidak adanya media penyimpanan yang baik. Oleh karena itu peneliti akan membuat sebuah aplikasi berbasis web yang akan menyimpan semua data pelanggan yang masuk serta dapat mencetak nota langsung didalamnya.
\end{abstract}

Kata kunci: aplikasi, data, komputer, servis

\section{PENDAhUluan}

Menyongsong era globalisasi pada saat sekarang ini, aplikasi komputer semakin dibutuhkan oleh organisasi maupun perusahaan. Banyaknya pekerjaan manusia yang dapat dibantu oleh komputer sehingga manusia dapat menjadi lebih produktif dan memberikan hasil kerja lebih baik dan lebih cepat sehingga dapat mempermudah kegiatan manusia. Khususnya dalam meningkatkan kualitas dan efektifitas aliran informasi dalam perusahaan, kontrol kualitas, dan menciptakan aliansi atau kerjasama dengan rekanan lainnya. Aplikasi komputer akan membantu organisasi maupun perusahaan dalam mengintegrasikan data, mempercepat dan mensistematisasi pengolahan data dan meningkatkan kualitas informasi serta kontrol manajemen.

Pesatnya perkembangan bisnis yang mengadaptasi teknologi informasi, mendorong terjadinya persaingan bisnis. Setiap pelaku bisnis bersaing untuk merebut pangsa pasar dan meraih pelanggan agar menggunakan produk atau jasa dari perusahaan mereka. Secara garis besar kebutuhan manusia akan komputer disaat ini sangatlah penting. Oleh karena itu hampir setiap orang mempunyai sebuah komputer untuk memaksimalkan pekerjaannya baik berupa personal komputer maupun yang lebih portabel seperti laptop dan tablet. Pada setiap teknologi pasti terdapat kekurangan, yaitu teknologi tersebut bisa rusak atau tidak berfungsi secara baik oleh karna umur dari teknologi tersebut maupun karna kesalahan penggunaan individunya. Oleh karena servis komputer sangat dibutuhkan dalam kondisi seperti ini.

Dalam hal ini Mellon Komputer adalah suatu toko komuter yang bergerak khusus pada servis komputer, di toko ini menerima berbagai macam kerusakan peralatan komputer baik itu 
personal komputer, laptop, tablet, printer, dan lain-lain. Pada saat ini pengelolaan data servis hanya bersifat manual, yaitu pelanggan datang untuk memperbaiki komputernya, kemudian data pelanggan dicatat pada sebuah nota, nota terdiri dari dua lembar yaitu lembar putih dan lembar merah. Lembar merah di bawa oleh pelanggan, sedangkan lembar putih disimpan di toko. Apabila sudah selesai maka pelanggan harus menunjukkan nota merah untuk mengambil komputer yang sudah selesai di servis.

Hal ini tentu saja memiliki kekurangan, yaitu data servis yang berupa nota tentu saja akan dapat hilang dan rusak, bahkan kesulitan bagi teknisi yaitu bagaimana mengingat data pelanggan dan data kerusakan komputer yang telah lalu, karna tidak adanya media penyimpanan yang baik. Oleh karena itu peneliti akan membuat sebuah aplikasi berbasis web yang akan menyimpan semua data pelanggan yang masuk serta dapat memprin nota langsung didalamnya.

\section{METODE PENELITIAN}

Metode waterfall sering disebut dengan siklus hidup klasik (classic life cycle), dimana hal ini menggambarkan pendekatan yang sistematis dan juga berurutan pada pengembangan perangkat lunak, dimulai dengan spesifikasi kebutuhan pengguna lalu berlanjut melalui tahapan-tahapan perencanaan (planning), permodelan (modeling), konstruksi (construction), serta penyerahan sistem ke para pengguna (deployment), yang diakhiri dengan dukungan pada perangkat lunak lengkap yang dihasilkan.

Pengembangan metode waterfall memiliki beberapa tahapan yang berurut yaitu: requirement (analisis kebutuhan), design system (desain sistem), coding (pengkodean) dan testing (pengujian), penerapan program, pemeliharaan.

Dalam pengembangan sistem ini, terdapat beberapa tahapan yang harus dilakukan, adapun tahapan tersebut adalah sebagai berikut:

\subsection{Analisa Sistem}

Dalam membangun aplikasi ini diperlukan perencanaan yang baik agar dihasilkan sistem yang dapat berjalan optimal. Tahap perencanaan ini terbagi atas 2 yaitu: a. Menentukan tujuan pembuatan aplikasi, tujuan penelitian ini adalah agar memberikan kemudahan baik bagi pemilik toko, teknisi maupun pelanggan untuk melakukan proses serah terima barang, deteksi kerusakan, maupun proses pencarian data pelanggan secara cepat.

b. Menentukan siapa yang akan menjadi pemakai, aplikasi data servis komputer ini dipakai oleh admin toko, kemudian dilanjutakan oleh teknisi dan terakhir pemilik toko untuk melihat data laporan.

\subsection{Perancangan Sistem}

Proses perancangan yang baik diperlukan untuk pembuatan program tak terkecuali dalam pembuatan aplikasi yang baik. Perancangan sistem secara terperinci, dilakukan dengan cara:

a. Rancangan Menu

b. Rancangan Database

c. Relasi Antar Tabel

d. Diagram Konteks

e. Data Flow Diagram (DFD)

f. Rancangan Tampilan

g. Rancangan Laporan

h. Pembuatan Program

Pembuatan data servis komputer ini dibuat menggunakan bahasa pemrograman PHP dan MySQL sebagai pengelola databasenya.

\subsection{Testing Aplikasi}

Pada tahap ini, dilakukan uji terhadap sistem yang telah selesai dibuat dengan menggunakan modem dan satu buah laptop server, setiap proses pendataan dilakukan langsung pada hosting dan domain yang telah disediakan sebelumnya.

\section{HASIL DAN PEMBAHASAN}

Aplikasi data servis komputer ini terdiri dari satu user admin tetapi user dapat datambahkan dan tidak terbatas. Aplikasi bisa di pakai secara offline maupun online. Agar dapat dijalankan secara online, dapat menggunakan sewa hosting dan domain yang banyak disediakan secara online.

\subsection{Rancangan Menu}

Rancangan menu pada aplikasi data servis komputer cukup sederhana, karena hanya 
mempunyai 1 level user saja. Berikut rancangan menu yang terbentuk dari aplikasi servis komputer:
1. Login
2. Home
3. Service
a. Input Service
b. Cari Data Service

4. Setting
a. Merk
b. Admin

5. About

6. Developer

7. Logout

\subsection{Rancangan Database}

Database dibuat menggunakan database MySQL dari aplikasi PHPMyAdmin dan diberi nama mellon, berikut tabel-tabel yang terbentuk dalam perancangan database:
1. Tabel Admin
2. Tabel Merk
3. Tabel Service

\subsection{Relasi Tabel}

Relasi antar tabel digunakan untuk melihat tabel-tabel mana saja yang terhubung. Berikut relasi antar tabel yang terbentuk dari aplikasi servis komputer:

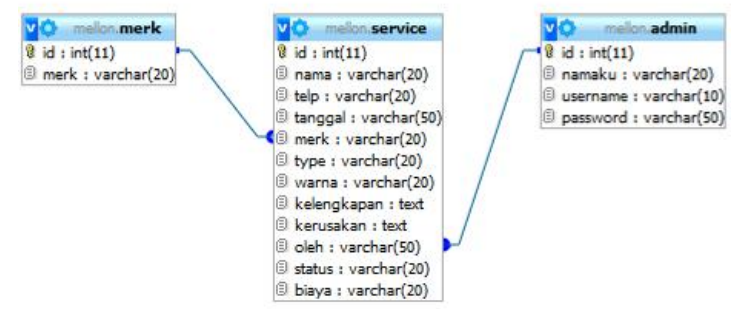

Gambar 1. Relasi Tabel

\subsection{Rancangan Tampilan}

Rancangan tampilan menggunakan template yang responsive, atau bisa digunakan disemua device, tampilan akan menyesuaikan sesuai ukuran layar device. Berikut tampilan yang terbentuk dari aplikasi servis komputer :
1. Halaman Login

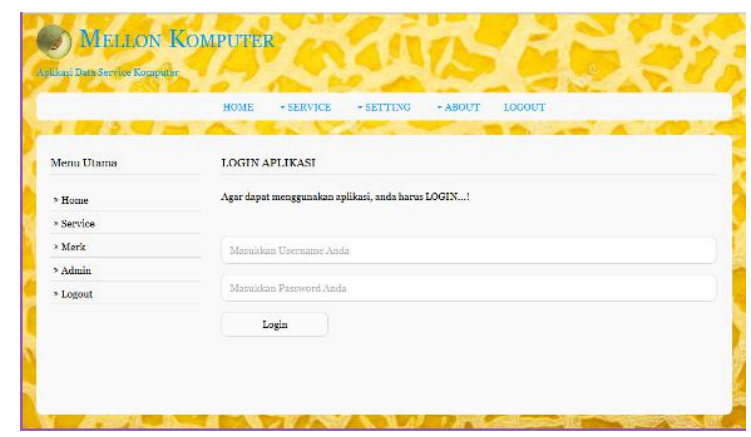

Gambar 2. Halaman Login

2. Input Data Servis

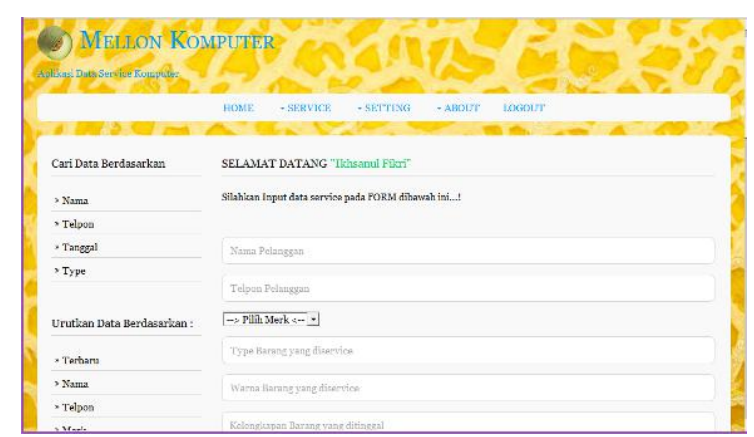

Gambar 3. Input Data Servis

3. Cari Data Servis

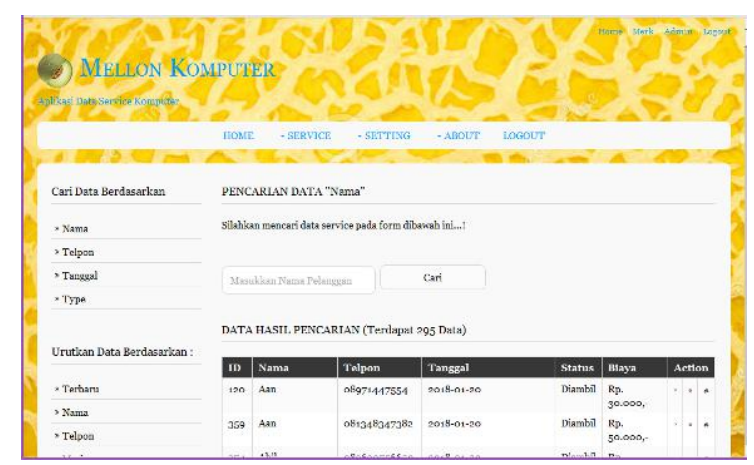

Gambar 4. Cari Data Servis

\section{Data Merk}

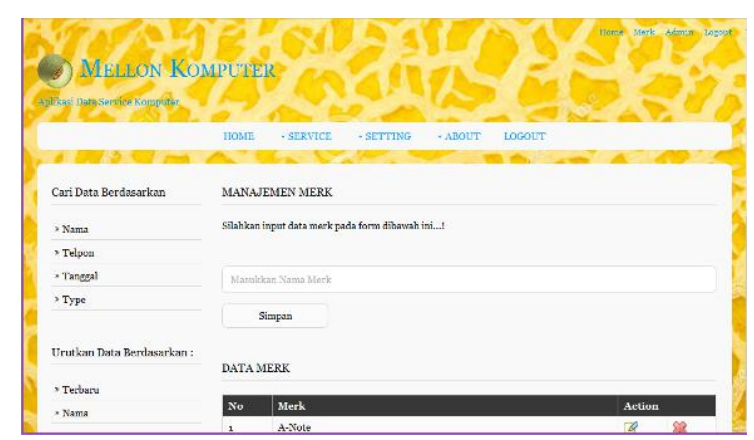

Gambar 5. Data Merk 
5. Data Admin

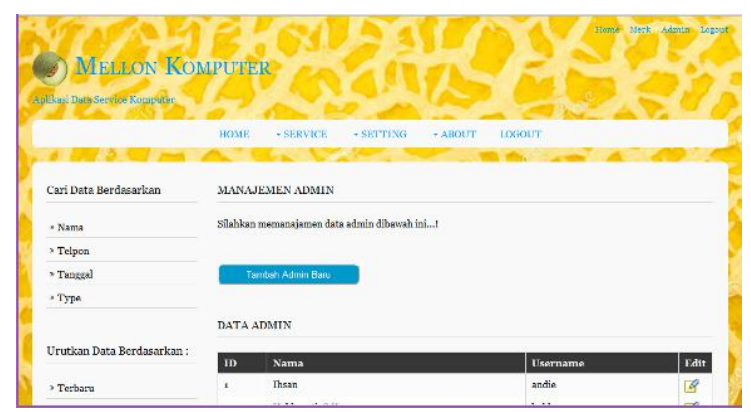

Gambar 6. Data Admin

6. Halaman Tentang Aplikasi

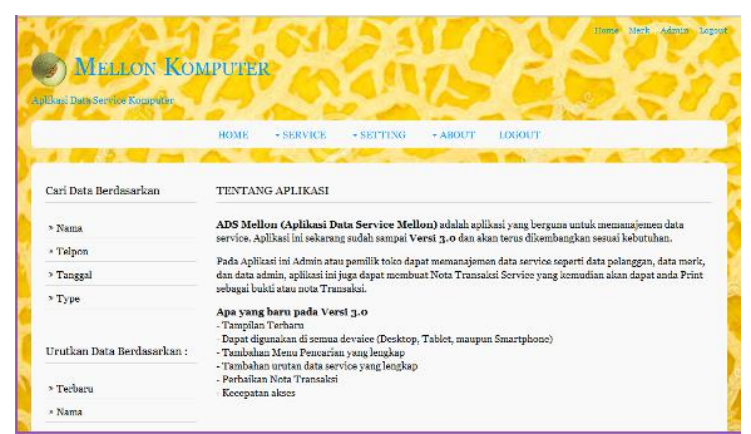

Gambar 7. Halaman Tentang Aplikasi

7. Halaman Developer

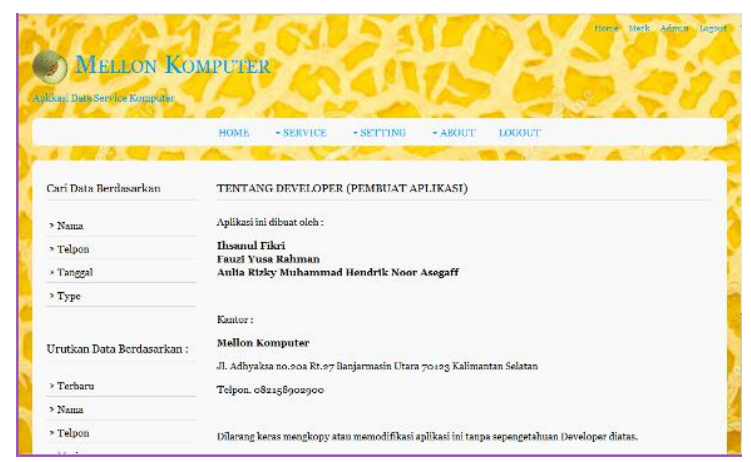

Gambar 8. Halaman Developer

\subsection{Rancangan Laporan}

Rancangan laporan pada aplikasi data servis komputer ini berupa nota servis yang dapat di print, berikut tampilannya:

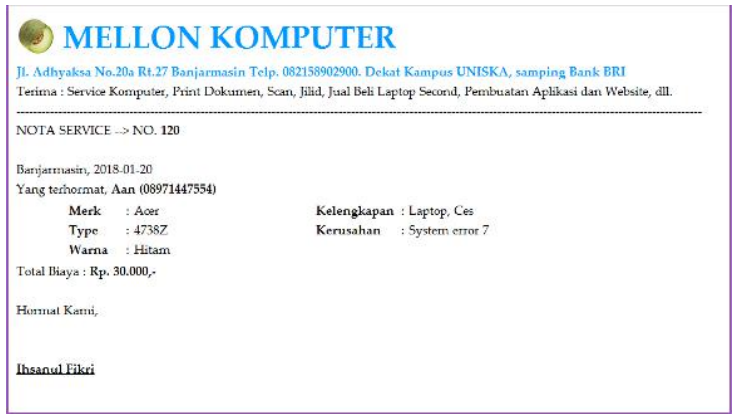

Gambar 9. Halaman Laporan

\section{KESIMPULAN}

Objek penelitian ini dilakukan di Mellon Komputer yang beralamat di jalan Adhyaksa No.20a RT.27 Banjarmasin. Mellon Komputer melayani jasa servis komputer, pengetikan, print, scan dokumen dan masih banyak lagi. Metode air terjun atau yang sering disebut metode waterfall sering dinamakan siklus hidup klasik (classic life cycle), dimana hal ini menggambarkan pendekatan yang sistematis dan juga berurutan pada pengembangan perangkat lunak, dimulai dengan spesifikasi kebutuhan pengguna lalu berlanjut melalui tahapan-tahapan perencanaan (planning), permodelan (modeling), konstruksi (construction), serta penyerahan sistem ke para pelanggan/pengguna (deployment), yang diakhiri dengan dukungan pada perangkat lunak lengkap yang dihasilkan.

Tujuan penelitian ini adalah agar memberikan kemudahan baik bagi pemilik toko, teknisi maupun pelanggan untuk melakukan proses serah terima barang, deteksi kerusakan, maupun proses pencarian data pelanggan secara cepat dan mudah. Aplikasi data servis komputer ini dipakai oleh admin toko, kemudian dilanjutakan oleh teknisi dan terakhir pemilik toko untuk melihat data laporan. Pembuatan data servis komputer ini dibuat menggunakan bahasa pemrograman PHP dan MySQL sebagai pengelola databasenya. Penggunakan aplikasi ternyata sangat memudahkan untuk mendata semua data servis dan menyimpan nota servis apabila sewaktu-waktu dibutuhkan. 


\section{DAFTAR PUSTAKA}

[1] Fatta, A., \& Hanif. (2007). Analisis \& Perancangan Sistem Informasi Untuk Keunggulan Bersaing perusahaan Organisasi Modern. Yogyakarta: ANDI.

[2] Hakim, Z. (2012, Agustus 16). Apa Itu Pemrograman Web? Retrieved Juli 2017, 2017, from Pemrograman Web: http://www.zainalhakim.web.id/posting/ apa-itu-pemrograman-web.html

[3] Kasiman, P. (2009). Aplikasi Web dengan PHP dan MySQL. Yogyakarta: ANDI.

[4] Martin, J. (1990). Information Enginering Book II Planning and Analysis 2nd Edition. New Jarsey: Prentice-Hall.

[5] Peranginangin, K. (2006). Aplikasi WEB dengan PHP dan MySQL. Yogyakarta: ANDI.

[6] Permana, B., \& dkk. (2011). Aplikasi Pengolahan Data Produksi Berbasis Web Di PT. Telehouse Engineering. Bandung: JBPTUNIKOMPP.

[7] Pressman, R. (2012). Rekayasa Perangkat Lunak - Buku Satu, Pendekatan Praktisi (Edisi 7). Yogyakarta: ANDI.

[8] Sunyoto, A. (2007). Pemrograman Database dengan Visual Basic dan Microsoft SQL. Yogyakarta: ANDI.

[9] Utami, E. (2005). Konsep Dasar Pengolahan dan Pemrograman Database dengan SQ1 Server, Ms. Access, dan Ms. Visual Basic. Yogyakarta: ANDI.

[10] Wikipedia. (2016, April 8). HTML. Retrieved Juli 12, 2017, from Wikipedia: http://id.wikipedia.org/wiki/HTML

[11] Wikipedia. (2016, Januari 3). PHP. Retrieved Juli 12, 2017, from Wikipedia: http://id.wikipedia.org/wiki/PHP 